\title{
Factors Associated with Compliance with Infection Control Guidelines in the Management of Labour by Healthcare Workers at Mulago Hospital, Uganda
}

\author{
Grace Komuhangi ${ }^{*}$, Nwana Uchechukwu Kevin², Ilori Oluwole Felex ${ }^{3}$, Lydia Kabiri ${ }^{4}$ \\ ${ }^{1}$ School of Nursing and Midwifery, Clarke International University, Kampala, Uganda \\ ${ }^{2}$ Department of Public Health, Victoria University, Kampala, Uganda \\ ${ }^{3}$ Department of Behavioral Science, Islamic University of Uganda, Kampala, Uganda \\ ${ }^{4}$ Department of Nursing, College of Health Sciences, Makerere University, Kampala, Uganda \\ Email: *gkomuhangi@ciu.ac.ug
}

How to cite this paper: Komuhangi, G., Kevin, N.U., Felex, I.O. and Kabiri, L. (2019) Factors Associated with Compliance with Infection Control Guidelines in the Management of Labour by Healthcare Workers at Mulago Hospital, Uganda. Open Journal of Nursing, 9, 697-723.

https://doi.org/10.4236/ojn.2019.97054

Received: May 8, 2019

Accepted: July 23, 2019

Published: July 26, 2019

Copyright $\odot 2019$ by author(s) and Scientific Research Publishing Inc. This work is licensed under the Creative Commons Attribution International License (CC BY 4.0).

http://creativecommons.org/licenses/by/4.0/

CC) (i) Open Access

\begin{abstract}
Globally, infections acquired during childbirth contribute to one tenth of the maternal deaths annually [1] [2]. Factors predisposing to high risks of puerperal infections include non-compliance with Standard Precautions of Infection Control (SPIC), unhygienic births by unskilled birth attendants, multiple vaginal examinations, prolonged labour and premature rapture of membranes [1]. The main purpose of this study was to determine factors associated with compliance to standard precautions of infection control the management of labour by healthcare workers in Mulago Hospital to generate information, which may be used in infection control and prevention practices. A cross-sectional study utilizing a quantitative approach was conducted among 115 healthcare workers. Consecutive sampling was done to include respondents in the study. Data were collected by direct observation and researcher administered questionnaires. Data were coded and entered into the computer using SPSS version 20 with programmed quality control checks. Descriptive data analyses, frequencies, cross tabulations and logistic regression analysis were the major statistical methods used. 103 healthcare workers were involved in the study, where $74 \%$ were females. Overall compliance was at $52 \%$, although it varied across domains. The majority of the healthcare workers (95.1\%) did not comply with hand hygiene. Being a male was associated with low compliance scores a cross most domains. One of the hospital factors which was significantly associated with compliance to hand hygiene was having had an in-service training with $p=0.008$ and $p=0.012$ at multivariate analysis. Overall compliance to standard precautions of infection control was
\end{abstract}


low compared to the Centre for Disease Control (CDC) recommendation. The findings in this study provide insight into individual and hospital related factors associated with compliance with standard precautions of infection control in the management of labour. There is an urgent need to put up interventions to improve on compliance with SPIC in management of labour among all healthcare workers.

\section{Keywords}

Compliance, Standard Precautions of Infection Control, Labour, Healthcare Workers

\section{Introduction}

Standard Precautions of Infection Control (SPIC) protocols replaced Universal Precautions and were formulated to be used in the care of all patients regardless of their diagnosis [3] [4]. According to WHO (2016), SPIC include: hand hygiene, use of Personal Protective Equipment (PPE), observing aseptic non-touch technique, disinfection and sterilization of reusable equipment and clothing used during patient care, environmental control (e.g., surface cleaning), health service waste handling, appropriate waste segregation of sharps, waste segregation excluding sharps, and isolation of patient's in accordance to requirement levels as an infection transmission source.

Compliance with SPIC in the management of labour by all healthcare workers in all health care facilities and other health service centres is very crucial in preventing maternal peripartum infections [3] [5]. The WHO (2016) highly recommends practice of asepsis in six areas also known "the six cleans" which include clean delivery surface, clean hands of the birth attendant, clean perineum of the mother, clean cord cutting instrument, clean cord ligature and clean cord care. In spite of the long period since the introduction of the SPIC, full compliance is still a matter of concern in many healthcare facilities [6].

Globally, infections acquired during childbirth process contribute to one tenth of the maternal deaths annually [1] [2]. These infections are one of the leading causes of maternal mortality and morbidity, with sepsis accounting for as much as $15 \%$ of the 289,000 maternal lives lost globally every year [7] [8].

Factors predisposing to high risks of puerperal infections include non-compliance with SPIC, unhygienic births by unskilled birth attendants, multiple vaginal examinations, prolonged labour and premature rapture of foetal membranes home [1]. Other factors also include the flora of the delivery room, and the types of antibiotics used, [9].

The situation is worse in developing countries where resources for healthcare delivery are limited [10]. Sub-Saharan Africa contributes three quarters of the global estimate for maternal sepsis related deaths [1] [11]. If death does not occur, these infections have been identified as a leading cause of maternal morbid- 
ity, prolonged hospital stay, chronic disability, chronic pelvic pain and secondary infertility [12].

In Uganda, the second leading cause of maternal mortality after haemorrhage is sepsis, where the mortality rate stands at $14 \%$ (UDHS, 2016). Many hospitals reports have indicated a big number of mothers admitted in the hospital receiving care during labour and childbirth, develop puerperal sepsis [11]. Evidence has suggested that all deaths as a result of sepsis are preventable through hygienic practices and delivery environments and these have been historically well documented [13]. Healthcare workers have been identified to be in a key position in the prevention of hospital acquired infections [7] [14].

Non-compliance with standard precautions of infection on the side of healthcare workers has been linked to lack of adequate training in infection control protocols, lack of supplies in the healthcare facilities and work overload [15]. Other studies have suggested that lack of appropriate knowledge of SPIC, lack of Personal Protective Equipment (PPE), low-risk perception and low perception of institutional safety environment are frequent factors linked to non-compliance to SPIC (Gammon et al., 2008).

The WHO highly recommends compliance with the standard precautions of infections control during management of labour by all healthcare workers. Compliance with standard precautions on the part of Healthcare Workers (HCWs) has been emphasized as fundamental and efficient means of healthcare-associated infections for both patients and healthcare workers [16].

Mortality rate in Uganda due to sepsis has overwhelmingly increased to almost double from $8 \%$ and $14 \%$ between four years (UDHS, 2016; UDHS, 2012). A recent study done in Mbarara regional referral and teaching hospital indicated that puerperal sepsis accounted for $30.9 \%$ of maternal deaths [11]. Yet healthcare workers are in a key position to preventing healthcare acquired infections [14]. This could be due to differences in professional background, inadequate training in SPIC, availability of standard operating procedures and work over load [15].

The existing evidence about the health care practitioners, infection control practices in the management of labour does not provide an in-depth insight about compliance with standard precautions of infection control.

In search for literature, there is paucity of data about this topic in maternity services although some studies have generally looked at general practices of SPIC in different areas of healthcare practice. Therefore, this study describes factors associated with compliance to standard precautions of infection control in the management of labour by healthcare workers at Mulago Hospital.

\section{Methods}

\subsection{Study Design}

This study utilized a descriptive cross sectional design of quantitative approaches, where the data from a population or a representative of subset is analyzed at 
specific point of time and the investigator measures the outcome and the exposure in the study participants at the same time (Gordis, 2009). Cross sectional study design is cheap and yet good at estimating the prevalence of the problem because data on the cause and outcome are collected at the same time [17]. This design was used because it is reliable at estimating the magnitude (compliance) and determinants of the phenomenon.

\subsection{Study Site}

The study was carried out in Mulago National Referral hospital, department of Obstetrics and Gynecology located in Kawempe Division, approximately $5 \mathrm{~km}$ from Kampala city center. It is the National Referral Hospital for the country and it handles all issues concerning women's health including prenatal care, postnatal, immunization, family planning, oncology and gynecology. The hospital conducts approximately 80 deliveries per day, 2400 deliveries per month and 28,800 deliveries per year (HMIS, 2017).

The clinical services delivered in this department (labour suite) per month are offered by HCWs of different professional cadres, which include 73 midwives, 19 obstetricians 42 Senior House Officers (SHO's), and 28 medical interns (total 163). This makes a total of $163 \mathrm{HCWs}$ who work in labour suites as per monthly duty roster (Hospital, 2017). There are two units in this department that deal with deliveries these include, low risk labour suite, high-risk labour suite. The mothers after delivery are transferred to post-natal unit and of these, a bigger proportion develop puerperal sepsis (HMIS, 2017).

\subsection{Study Population}

The study population comprised of HCWs (midwives, nurse midwives, intern nurses and midwives, senior house officers, obstetricians) who are 163 in total as per monthly duty roster (Hospital labour suite, statistics) at Mulago hospital working in the department of obstetrics and gynecology in labour suite units.

\subsection{Inclusion Criteria}

The study included HCWs (Nurses, midwives, intern nurses, nurse/midwives, intern doctors, obstetricians and senior house officers) who are involved in the management of labour.

\subsection{Exclusion Criteria}

The study excluded healthcare workers who are sick, those on leave and those busy with administrative work.

\subsection{Sampling Procedure}

The study utilized non probability quota sampling proportionate to size using convenience sampling. A fair representation of all cadres was considered by selecting a participant from all cadres to be included in the study. The first res- 
pondent was picked on as she/he commences on her shift. No respondent declined in participating in the study if they met the inclusion criterion until the desired sample size was achieved.

\subsection{Sample Size Determination}

The number of study subjects was estimated using Kish \& Leslie (1969) formula for homogeneous population who are in single study group with proportion outcome variable.

$$
N=\frac{z^{2} p q}{d^{2}}
$$

where:

$N=$ the required sample size

$z=$ the $z$ score corresponding to $95 \%$ confidence level (1.96).

$p=$ proportion complying with standard precautions of infection control among healthcare workers in Kenya.

$q=1-p$ (the expected proportion of the study population who do not comply with standard precautions for infection control.

$d=$ degree of precision in the study.

This formula was used to calculate $N$ for this study, basing on the following evidence from studies carried out before.

The confidence level of the researcher in this study was at 95\% (Hence $z=$ 1.96).

Compliance among healthcare workers in Tanzania stands at 49.7\% [18].

Hence $p=0.497$, the proportion, $q(1-p)$ will be $1-0.479=0.503$ hence $q=$ 0.503 in this study.

The degree of precision in the study was estimated at $5 \%$ (Hence $d=0.05$ ).

Substituting in the above formula, therefore:

$$
N=\frac{1.96^{2} \times 0.497 \times 0.503}{0.05^{2}}=384
$$

Since the sample, size was higher than the number of the healthcare workers who are on a monthly roster of the two labour suites of Mulago hospital

The required sample size was calculated using a formula for infinite populations. Considering the finite population correction factor;

$$
n=\frac{n_{0} \cdot N}{n_{0}+(N-1)}
$$

where $n=$ required sample size, $n_{0}=384$ and $N=163$, therefore by substituting in the above formula, the required sample size $n=163$ respondents

$$
N=\frac{384 \times 163}{384+(163-1)}=115
$$

Hence, the sample size was 115 participants

For representativeness, Probability Proportionate to Size (PPS) was considered. 


\begin{tabular}{cc}
\hline Cadres & Calculations by sample size \\
\hline Midwives 70 & $\frac{70}{163} \times 115=49$ \\
Obstetricians 19 & $\frac{19}{163} \times 115=13$ \\
Senior house officers 37 & $\frac{37}{163} \times 115=26$ \\
Medical interns 28 & $\frac{28}{163} \times 115=27$ \\
TOTAL $=163$ & TOTAL $=115$ \\
\hline
\end{tabular}

\subsection{Definition and Measurement of Variables}

\subsubsection{Dependent Variables}

The primary outcome was compliance with Standard precautions of infection control in management of labour. This was measured as a categorical variable using an observation checklist modified from observation checklist for CDC (2008) and a modification from the validated observation checklist [5].

Assessment of compliance was by participant direct observation based on indication and corresponding action. An indication refers to a situation in which an infection prevention and control practice must be undertaken to prevent the risk of a pathogen being transmitted from one surface to another (see Appendix I). Actions occur in response to indications, such that each indication has a corresponding action.

Compliance means that the correct action has been taken. For example, for the domain of hand hygiene (Table 1 of the observation checklist), the indication "Before touching the patient" indicates the possibility that physical contact could lead to microbial transmission. The correct action corresponding to this indication is "Health-care worker washed his or her hands with soap and water or used an alcohol-based hand rub).

\subsubsection{Independent Variables}

Independent variables associated with compliance to SPIC include: socio-demographics variables include gender and professional category, qualification, cadre, work these were measured using a questionnaire (see Appendix II).

\subsection{Data Collection Methods}

This was a non-intrusive as the healthcare workers were left to do what they usually do while practicing infection control and prevention measures in labour suite unless there is a life-threatening event that forces the observer to intervene. If this happened, then that case would be dropped, but this never happened throughout the study. During the direct observation by the principal investigator created a rapport with the study participant to pave a way to ask the few questions which are in the questionnaire indirectly in a manner that the respondent never considered this an observation of their practices. The observed data was 
entered on the checklist immediately to avoid recall bias. This method was adopted from a study which was done in Nigeria [1].

Every day, at least 2 healthcare workers study participants were observed and interviewed. Data were collected between February and April 2018.

One respondent was observed at a time throughout the three procedures. The four main procedures considered included; physical examination, vaginal examinations, invasive procedures and conducting delivery. The six infection control and prevention domains were observed across these procedures. The domains have been identified as crucial for the safety of patients and HCWs by WHO, CDC and the Ugandan Ministry of Health and these are:

1) Hand hygiene;

2) Use of personal protective equipment;

3) Disinfection of reusable equipment and cleaning of delivery surfaces

4) Waste segregation of sharps

5) Waste segregation excluding sharps and,

6) The non-touch technique.

For each of these domains, compliance with Standard Precautions of Infection control (SPIC) as practiced by the healthcare workers. Each domain was scored as either "Yes" for complied or "No "not complied after the respondent has scored all. The direct observation was done without the knowledge of the study participants in order to avoid change of behavior in their SPIC practices.

\subsection{Data Collection Procedure}

Administrative clearance from Mulago hospital institutional review board was sought. Institutional consent was obtained from the unit managers to minimize on the change of behavior. Healthcare workers were identified by use of a duty roster before a shift. Since the study was unobtrusive (covert) direct observation, deferred consent was sought after the study where the principal investigator debriefed the participants about the study and the findings and asked them whether they would allow their findings be used for data analysis. In addition, those who objected this their findings were not included for data analysis.

\subsection{Data Collection Tools}

An observation checklist was modified from CDC (2008) infection control assessment tool and a validated observation checklist of a study, which was done in Kenya, to assess compliance by practices of the HCWs on SPIC [5].

A pilot study of 10 HCWs was conducted at Naguru Regional Referral Hospital labour ward, which has similar characteristics as the study area to test the tool for validity and reliability.

\subsection{Quality Control Measures}

The Principal Investigator collected data in order to avoid bias by other researchers and directly observed the performance of HCWs to avoid change of 
behavior of HCWs during performing of routine procedures.

The questionnaire was pretested before data collection on 10 HCWs from Naguru hospital since it has similar characteristics of being also a referral facility as Mulago national referral hospital.

To improve validity/reliability of data collection on observational studies, the principal investigator through participative observation offered an assistive role to the healthcare worker performing the procedure. Interviews were conducted alongside the participative by the principal investigator. This was adopted as strategy to minimize the Wharthone's effect.

Quality of data collected was ensured by cross checking completeness of the data checklist and the questionnaire, which was used to assess the individual and facility factors. The principal investigator also crosschecked all filled data collection tools at the end of each data collection shift.

\subsection{Data Management and Analysis}

Data collected was entered, cleaned and analyzed using SPSS version 20 to generate descriptive statistics.

Overall compliance and non-compliance was calculated by adding up all percentages from each domain then divided by the total number of domains which was 6 this method was obtained from different studies which were conducted on compliance with infection control practices [5].

A binary score of yes (performed) and no (not performed) were used for the six domains of SPIC.

In addition, to generate descriptive statistics, categorical variables were described in form of frequencies, percentages and texts.

For objective one, data was analyzed to yield percentages of compliance of respondents and was be presented in form of a table and pie chart.

The objective two and three data were analyzed by chi square test/cross tabulation to yield frequencies, percentages and $p$-values for each SPIC domain. This method was utilized because the some of the data had no values hence this would not yield the Odds Ratios (OR) and Confidence Intervals (CI).

\subsection{Ethical Considerations}

Approval to do the study was sought from the School of Health Sciences Research and Ethics Committee/institutional review board (SHREC:REF: 2017:057.) An administrative clearance was obtained from Mulago Hospital research and ethics committee. The approval letters from the School of Health Sciences REC and administrative clearance from Mulago hospital were presented to the clinical head of and of obstetrics and gynecology of Mulago national referral hospital.

Differed consent was sought after the study where the principal investigator debriefed the participants about the study and the findings and asked them whether they would allow their findings be used for data analysis. Those who objected this their findings were not included for data analysis. 


\section{Results}

\section{Social Demographic Characteristics/Individual Factors of the Respondents}

The study involved 115 but only data for 103 respondents who offered differed consent were analyzed. Majority of the participants were females (74\%). Most of the respondents were midwives (44\%) and almost a half of the respondents (48\%) were bachelor's degree holders as a level of academic qualification. Half of the study participants (51\%) worked in other health facilities/multiple places. Other characteristics are presented in Table 1 below.

In Table 2, majority (84\%) of the healthcare workers had not seen the standard operating procedures (SOPs) at the facility. Moreover, majority (65\%) had not had an in-service training on SPIC.

Table 3, shows proportions of compliance with SPIC by health care workers in management of labour in the six domains which are hand hygiene, personal protective equipment, equipment processing and surfaces, waste segregation of sharps, waste segregation excluding sharps and the non-touch technique. Study results show that the majority (95.1\%) of the HCWs did not comply with hand hygiene compared to other domains of SPIC in the management of labour. However, the observation tool captured that majority (94.2\%) of the HCWs complied with use of PPE and $77.7 \%$ complied with waste segregation of sharps.

Table 1. Social Demographic Characteristics/individual factors of the respondents.

\begin{tabular}{|c|c|c|}
\hline Characteristics & Frequency $(n=103)$ & Percentage (\%) \\
\hline \multicolumn{3}{|l|}{ Gender } \\
\hline Male & 27 & 26 \\
\hline Female & 76 & 74 \\
\hline \multicolumn{3}{|l|}{ Professional cadre } \\
\hline Midwife & 45 & 44 \\
\hline Obstetrician & 34 & 33 \\
\hline Medical Intern & 24 & 23 \\
\hline \multicolumn{3}{|l|}{ Qualification level } \\
\hline Master's degree & 11 & 11 \\
\hline Bachelor's degree & 49 & 47 \\
\hline Diploma \& Certificate & 43 & 42 \\
\hline \multicolumn{3}{|l|}{ Work experience (in years) } \\
\hline $2-4$ & 13 & 13 \\
\hline $5-10$ & 39 & 38 \\
\hline$>10$ & 29 & 28 \\
\hline \multicolumn{3}{|l|}{ Work in other facilities } \\
\hline Yes & 53 & 51 \\
\hline No & 50 & 49 \\
\hline
\end{tabular}


Table 2. Characteristics of the hospital factors.

\begin{tabular}{ccc}
\hline Characteristics & Frequency $(\boldsymbol{n}=\mathbf{1 0 3})$ & Percentage (\%) \\
\hline Seen any SOPs of infection control/prevention & 17 & 17 \\
Yes & 86 & 84 \\
No & & \\
Had in-service training on SPIC & 65 & 63 \\
Yes & 38 & 37 \\
\hline
\end{tabular}

Proportions of compliance with standard precautions of infection control in management of labour by healthcare workers.

Table 3. Level of compliance with standard precautions of infection control in the management of labour by healthcare workers.

\begin{tabular}{|c|c|c|}
\hline Variables & Frequency & $\%$ (95\% Confidence Interval) \\
\hline \multicolumn{3}{|l|}{ Hand hygiene } \\
\hline Compliance & 5 & $4.9(2-11)$ \\
\hline Non compliance & 98 & $95.1(89-98)$ \\
\hline \multicolumn{3}{|c|}{ Use Personal Protecting Equipment } \\
\hline Compliance & 97 & $94.2(88-97)$ \\
\hline Non compliance & 6 & $5.8(3-12)$ \\
\hline \multicolumn{3}{|c|}{$\begin{array}{l}\text { Equipment processing of non-re-usable } \\
\text { equipment \& cleaning delivery surfaces }\end{array}$} \\
\hline Compliance & 26 & $25.2(18-34)$ \\
\hline Non compliance & 77 & $74.8(66-82)$ \\
\hline \multicolumn{3}{|c|}{ Waste segregation of sharps } \\
\hline Compliance & 80 & $77.7(69-85)$ \\
\hline Non compliance & 23 & $22.3(15-31)$ \\
\hline \multicolumn{3}{|c|}{ Waste segregation excluding sharps } \\
\hline Compliance & 62 & $60.2(51-69)$ \\
\hline Non compliance & 41 & $39.8(31-49)$ \\
\hline \multicolumn{3}{|l|}{ Non touch technique } \\
\hline Compliance & 52 & $50.6(41-60)$ \\
\hline Non compliance & 51 & $49.4(40-59)$ \\
\hline
\end{tabular}

\section{Univariate Analysis}

Univariate was the primary analysis and the variables associated with the outcome. To obtain proportions of compliance and the $p$-values were also obtained from the chi-square for each domain. Compliance and the associated factors were presented in tables mentioned below. This method was utilized to calculate for frequencies, percentages and $p$-values. This method was preferred because majority of the data had zero values and hence could not be run in logistic re- 
gression to obtain odds ratios and confidence intervals. Table 4 below indicates hand hygiene and use of personal protective equipment.

Individual factors associated with standard precautions of infection control in management of labour among healthcare workers at univariate analysis.

Table 4 below indicate that females complied with hand hygiene compared to the males who did not comply at all, while the bachelor's holders (100\%) were likely to comply than other levels of qualification. Results also indicate that work in different places was statistically associated with compliance to hand hygiene ( $p$-value 0.018$)$. In the same Table 4 below results indicate that majority of the females (73\%) used Personal Protecting Equipment (PPE).

In Table 5, results indicate majority of the females complied to equipment processing compared to their male counterparts and gender was significantly

Table 4. Individual factors associated with hand hygiene.

\begin{tabular}{|c|c|c|c|c|c|c|}
\hline \multirow{2}{*}{ Variables } & \multicolumn{2}{|c|}{$\begin{array}{l}\text { Hand hygiene } \\
\text { Compliance }\end{array}$} & \multirow{2}{*}{$p$-value } & \multicolumn{2}{|c|}{$\begin{array}{l}\text { Use of PPE } \\
\text { Compliance }\end{array}$} & \multirow{2}{*}{$p$-value } \\
\hline & $\begin{array}{c}\text { Yes } \\
n=5(\%)\end{array}$ & $\begin{array}{c}\text { No } \\
n=98(\%)\end{array}$ & & $\begin{array}{c}\text { Yes } \\
n=97(\%)\end{array}$ & $\begin{array}{c}\text { No } \\
n=6(\%)\end{array}$ & \\
\hline \multicolumn{7}{|l|}{ Gender } \\
\hline Male & $0(0)$ & $27(28)$ & \multirow{2}{*}{0.172} & $24(25)$ & $3(50)$ & \multirow{2}{*}{0.172} \\
\hline Female & $5(100)$ & $71(72)$ & & $73(75)$ & $3(50)$ & \\
\hline \multicolumn{7}{|l|}{ Professional cadre } \\
\hline Midwife & $1(20)$ & $44(45)$ & \multirow{3}{*}{0.137} & $45(46)$ & $0(00)$ & \multirow{3}{*}{0.073} \\
\hline Obstetrician & $1(20)$ & $33(34)$ & & $30(31)$ & $4(67)$ & \\
\hline Medical intern & $3(60)$ & $21(21)$ & & $2(23)$ & $2(33)$ & \\
\hline \multicolumn{7}{|l|}{ Qualification level } \\
\hline Bachelor's Degree & $5(100)$ & $44(45)$ & \multirow{3}{*}{0.055} & $44(45)$ & $5(83)$ & \multirow{3}{*}{0.101} \\
\hline Master's Degree & $0(00)$ & $11(11)$ & & $10(10)$ & $1(17)$ & \\
\hline Diploma and Certificate & $0(00)$ & $43(44)$ & & $43(44)$ & $0(00)$ & \\
\hline \multicolumn{7}{|l|}{$\begin{array}{l}\text { Work experience } \\
\text { (in years) }\end{array}$} \\
\hline$\leq 1$ & $2(40)$ & $20(20)$ & \multirow{4}{*}{0.648} & $20(21)$ & $2(33)$ & \multirow{4}{*}{0.839} \\
\hline $2-4$ & $1(20)$ & $12(12)$ & & $12(12)$ & $1(17)$ & \\
\hline $5-10$ & $1(20)$ & $38(39)$ & & $37(38)$ & $2(33)$ & \\
\hline$>10$ & $1(20)$ & $28(29)$ & & $28(29)$ & $1(17)$ & \\
\hline \multicolumn{7}{|l|}{$\begin{array}{l}\text { Work in multiple } \\
\text { facilities }\end{array}$} \\
\hline Yes & $0(0)$ & $53(54)$ & \multirow{2}{*}{$0.018^{*}$} & $49(51)$ & $4(67)$ & \multirow{2}{*}{0.442} \\
\hline No & $5(100)$ & $45(56)$ & & $48(49)$ & $2(33)$ & \\
\hline
\end{tabular}

$p$-values obtained from chi-square test/cross tabulation to indicate the frequencies, percentages and $p$-values. *indicates significant findings because the $\mathrm{p}$-valve is $<0.05$. 
Table 5. Individual factors associated with disinfection of re-usable equipment, and waste segregation of sharps.

\begin{tabular}{|c|c|c|c|c|c|c|}
\hline \multirow[t]{2}{*}{ Variables } & \multicolumn{2}{|c|}{$\begin{array}{c}\text { Disinfection of re-usable } \\
\text { equipment } \& \text { cleaning } \\
\text { delivery surfaces, } \\
\text { Compliance }\end{array}$} & \multirow[t]{2}{*}{$p$-value } & \multicolumn{2}{|c|}{$\begin{array}{c}\text { Waste segregation } \\
\text { of sharps } \\
\text { Compliance }\end{array}$} & \multirow[t]{2}{*}{$p$-value } \\
\hline & $\begin{array}{c}\text { Yes } \\
n=26(\%)\end{array}$ & $\begin{array}{c}\text { No } \\
n=77(\%)\end{array}$ & & $\begin{array}{c}\text { Yes } \\
n=80(\%)\end{array}$ & $\begin{array}{c}\text { No } \\
n=23(\%)\end{array}$ & \\
\hline \multicolumn{7}{|l|}{ Gender } \\
\hline Female & $23(88)$ & $\begin{array}{l}24(31) \\
53(69)\end{array}$ & $0.049^{*}$ & $\begin{array}{l}18(23) \\
62(77)\end{array}$ & $\begin{array}{c}9(39) \\
14(61)\end{array}$ & 0.110 \\
\hline \multicolumn{7}{|l|}{ Professional cadre } \\
\hline Midwife & $15(58)$ & $30(39)$ & \multirow{3}{*}{0.241} & $36(45)$ & $9(39)$ & \multirow{3}{*}{$0.046^{*}$} \\
\hline Obstetrician & $6(23)$ & $28(36)$ & & $22(28)$ & $12(52)$ & \\
\hline Medical intern & $5(19)$ & $19(25)$ & & $22(28)$ & $2(9)$ & \\
\hline \multicolumn{7}{|l|}{ Qualification level } \\
\hline Bachelor's Degree & $15(58)$ & $30(39)$ & \multirow{3}{*}{0.241} & $36(45)$ & $9(39)$ & \multirow{3}{*}{$0.046^{*}$} \\
\hline Master's Degree & $6(23)$ & $28(36)$ & & $22(28)$ & $12(52)$ & \\
\hline Diploma and Certificate & $5(19)$ & $19(25)$ & & $22(28)$ & $2(9)$ & \\
\hline \multicolumn{7}{|l|}{$\begin{array}{l}\text { Work experience } \\
\text { (in yrs.) }\end{array}$} \\
\hline$\leq 1$ & $4(15)$ & $18(23)$ & \multirow{4}{*}{0.705} & $18(23)$ & $4(17)$ & \multirow{4}{*}{0.148} \\
\hline $2-4$ & $4(15)$ & $9(12)$ & & $8(10)$ & $5(22)$ & \\
\hline $5-10$ & $9(35)$ & $30(39)$ & & $28(35)$ & $11(48)$ & \\
\hline$>10$ & $9(35)$ & $20(26)$ & & $26(32)$ & $3(13)$ & \\
\hline \multicolumn{7}{|l|}{$\begin{array}{l}\text { Work in multiple } \\
\text { facilities }\end{array}$} \\
\hline Yes & $13(50)$ & $40(52)$ & \multirow{2}{*}{0.864} & $40(50)$ & $13(57)$ & \multirow{2}{*}{0.581} \\
\hline No & $13(50)$ & $37(48)$ & & $40(50)$ & $10(43)$ & \\
\hline
\end{tabular}

$p$-values obtained from chi-square test/cross tabulation to indicate the frequencies, percentages and $p$-values. *indicates significant findings because the $\mathrm{p}$-valve is $<0.05$.

associated with compliance to equipment processing ( $p$-value 0.049 ). In the same Table 5, it is indicated that majority of the people who complied with waste segregation of sharps were females (62\%). Professional cadre and level of qualification were also statistically associated with this same domain ( $p$-values 0.046 and 0.046 ) respectively.

Table 6, results show that most females (60\%) complied to waste segregation of sharps and it is also indicated that gender was statistically associated with compliance with this same domain of SPIC ( $p$-value $<0.000$ ). It is also indicated that the majority in the professional cadre who complied were midwives (44\%). the same variable, professional cadre and level of qualification were statistically associated with compliance to waste of sharps ( $p$-values $<0.00$ and $<0.001$ 
Table 6. Individual factors associated with waste segregation excluding sharps and observing aseptic non-touch technique.

\begin{tabular}{|c|c|c|c|c|c|c|}
\hline \multirow{2}{*}{ Variables } & \multicolumn{2}{|c|}{$\begin{array}{l}\text { Waste segregation } \\
\text { excluding sharps } \\
\text { Compliance }\end{array}$} & \multirow[t]{2}{*}{$p$-value } & \multicolumn{2}{|c|}{$\begin{array}{c}\text { Aseptic Non-Touch } \\
\text { technique } \\
\text { Compliance }\end{array}$} & \multirow[t]{2}{*}{$p$-value } \\
\hline & $\begin{array}{c}\text { Yes } \\
n=62(\%)\end{array}$ & $\begin{array}{c}\text { No } \\
n=41(\%)\end{array}$ & & $\begin{array}{c}\text { Yes } \\
n=52(\%)\end{array}$ & $\begin{array}{c}\text { No } \\
n=51(\%)\end{array}$ & \\
\hline \multicolumn{7}{|l|}{ Gender } \\
\hline $\begin{array}{c}\text { Male } \\
\text { Female }\end{array}$ & $60(97)$ & $\begin{array}{l}25(61) \\
16(39)\end{array}$ & $<0.000^{*}$ & $\begin{array}{l}16(31) \\
36(69)\end{array}$ & $\begin{array}{l}11(22) \\
40(78)\end{array}$ & 0.288 \\
\hline \multicolumn{7}{|l|}{ Professional cadre } \\
\hline Midwife & $44(71)$ & $1(2)$ & & $15(29)$ & $30(59)$ & \multirow{3}{*}{$0.007^{*}$} \\
\hline Obstetrician & $2(2)$ & $32(78)$ & \multirow[t]{2}{*}{$<0.000^{*}$} & $23(44)$ & $11(21)$ & \\
\hline Medical intern & $16(26)$ & $8(20)$ & & $14(27)$ & $10(20)$ & \\
\hline \multicolumn{7}{|l|}{ Qualification level } \\
\hline Bachelor's Degree & $20(32)$ & $29(71)$ & \multirow{3}{*}{$<0.001^{*}$} & $28(54)$ & $21(41)$ & \multirow{3}{*}{$0.009^{*}$} \\
\hline Master's Degree & $0(00)$ & $11(27)$ & & $9(17)$ & $2(4)$ & \\
\hline Diploma and Certificate & $42(68)$ & $1(2)$ & & $15(29)$ & $28(55)$ & \\
\hline \multicolumn{7}{|l|}{$\begin{array}{l}\text { Work experience } \\
\text { (in yrs.) }\end{array}$} \\
\hline$\leq 1$ & $12(19)$ & $10(24)$ & \multirow{4}{*}{0.422} & $12(23)$ & $10(20)$ & \multirow{4}{*}{0.169} \\
\hline $2-4$ & $10(16)$ & $3(6)$ & & $4(8)$ & $9(18)$ & \\
\hline $5-10$ & $21(34)$ & $18(46)$ & & $24(46)$ & $15(29)$ & \\
\hline$>10$ & $19(31)$ & $10(24)$ & & $12(23)$ & $17(33)$ & \\
\hline \multicolumn{7}{|l|}{$\begin{array}{l}\text { Work in multiple } \\
\text { facilities }\end{array}$} \\
\hline Yes & $23(37)$ & $30(73)$ & \multirow[b]{2}{*}{$<0.000^{*}$} & $28(54)$ & $25(49)$ & \multirow[b]{2}{*}{0.624} \\
\hline No & $39(63)$ & $11(27)$ & & $24(46)$ & $26(51)$ & \\
\hline
\end{tabular}

$p$-values obtained from chi-square test/cross tabulation to indicate the frequencies, percentages and $p$-values. *indicates significant findings because the $\mathrm{p}$-valve is $<0.05$.

respectively). In the same Table 6 results indicated, that and observing the non-touch technique was statistically associated with professional cadre and level of qualification with $p$-values of 0.007 and 0.009 respectively.

Table 7 shows the Hospital/Facility related factors associated with standard precaution of infection control in management of labour among healthcare workers. It is indicated that having had an in-service training was significantly associated with complying to hand hygiene $(p=0.018)$.

Table 8 results show the factors associated with hospital factors and compliance with disinfection of re-usable equipment and waste segregation of sharps. The results show that majority of the non-compliance with disinfection of reusable equipment (84\%) of the HCWs had not seen SOPs, while $69 \%$ had not received an in-service training on SPIC. 
Table 7. Hospital/facility factors associated with Hand hygiene technique and use of Personal protecting equipment.

\begin{tabular}{|c|c|c|c|c|c|c|}
\hline \multirow{2}{*}{ Variables } & \multicolumn{2}{|c|}{$\begin{array}{c}\text { Hand hygiene } \\
\text { Compliance }\end{array}$} & \multirow{2}{*}{$P$-value } & \multicolumn{2}{|c|}{$\begin{array}{l}\text { Use of PPE } \\
\text { Compliance }\end{array}$} & \multirow{2}{*}{$p$-value } \\
\hline & $\begin{array}{c}\text { Yes } \\
(n=5)\end{array}$ & $\begin{array}{c}\text { No } \\
(n=98)\end{array}$ & & $\begin{array}{c}\text { Yes } \\
(n=97)\end{array}$ & $\begin{array}{c}\text { No } \\
(n=6)\end{array}$ & \\
\hline \multicolumn{7}{|c|}{$\begin{array}{l}\text { Seen any SOPs of infection } \\
\text { control/prevention }\end{array}$} \\
\hline Yes & $0(0)$ & $17(17)$ & \multirow{2}{*}{0.308} & $17(18)$ & $0(0)$ & \multirow{2}{*}{0.262} \\
\hline No & $5(100)$ & $81(83)$ & & $80(82)$ & $6(100)$ & \\
\hline \multicolumn{7}{|c|}{$\begin{array}{l}\text { Had in-service } \\
\text { training SOPs }\end{array}$} \\
\hline Yes & $4(80)$ & $29(30)$ & \multirow{2}{*}{$0.018^{*}$} & $30(31)$ & $3(50)$ & \multirow{2}{*}{0.331} \\
\hline No & $1(20)$ & $69(70)$ & & 67 (69) & $3(50)$ & \\
\hline
\end{tabular}

$p$-values obtained from chi-square test/cross tabulation to indicate the frequencies, percentages and $p$-values. *indicates significant findings because the $\mathrm{p}$-valve is $<0.05$.

Table 8. Hospital/facility factors associated with disinfection of re-usable equipment and cleaning of delivery surfaces and waste segregation of sharps.

\begin{tabular}{|c|c|c|c|c|c|c|}
\hline \multirow[t]{2}{*}{ Variables } & \multicolumn{2}{|c|}{$\begin{array}{l}\text { Disinfection of } \\
\text { re-usable \& cleaning } \\
\text { delivery surfaces } \\
\text { compliance }\end{array}$} & \multirow[t]{2}{*}{$P$-value } & \multicolumn{2}{|c|}{$\begin{array}{c}\text { waste segregation of } \\
\text { sharps } \\
\text { Compliance }\end{array}$} & \multirow[t]{2}{*}{$p$-value } \\
\hline & $\begin{array}{c}\text { Yes } \\
n=26(\%)\end{array}$ & $\begin{array}{c}\text { No } \\
n=77(\%)\end{array}$ & & $\begin{array}{c}\text { Yes, } \\
n=80(\%)\end{array}$ & $\begin{array}{c}\text { No, } \\
n=23(\%)\end{array}$ & \\
\hline \multicolumn{7}{|c|}{$\begin{array}{l}\text { Seen any SOPs of } \\
\text { infection } \\
\text { control/prevention }\end{array}$} \\
\hline $\begin{array}{l}\text { Yes } \\
\text { No }\end{array}$ & $\begin{array}{l}5(19) \\
21(81)\end{array}$ & $\begin{array}{l}12(16) \\
65(84)\end{array}$ & 0.665 & $\begin{array}{l}14(18) \\
66(82)\end{array}$ & $\begin{array}{l}3(13) \\
20(87)\end{array}$ & 0.612 \\
\hline \multicolumn{7}{|l|}{$\begin{array}{l}\text { Had in-service } \\
\text { training SOPs }\end{array}$} \\
\hline Yes & $9(35)$ & $24(31)$ & 0.745 & $24(30)$ & $\begin{array}{l}9(39) \\
14(61)\end{array}$ & 0.408 \\
\hline
\end{tabular}

$p$-values obtained from chi-square test.

In Table 9, results show that majority of the people (74\%) who complied with wate segregation excluding sharps had had an inservice training.

\section{Bivariate Analysis}

Individual factors associated with compliance to standard precautions of infection control in management of labour among healthcare workers at bivariate analysis was done for those variables that had numbers that can be computed to get the odds ratios and confidence intervals and aggregated results are shown in Table 10.

The results indicated in Table 10, show that those who have had a work 
Table 9. Hospital/facility factors associated with waste segregation excluding sharps andaseptic Non-Touch Technique.

\begin{tabular}{|c|c|c|c|c|c|c|}
\hline \multirow[t]{2}{*}{ Variables } & \multicolumn{2}{|c|}{$\begin{array}{l}\text { waste segregation } \\
\text { excluding sharps } \\
\text { Compliance }\end{array}$} & \multicolumn{3}{|c|}{$\begin{array}{c}\text { Aseptic Non-Touch } \\
\text { Technique } \\
\text { Compliance }\end{array}$} & \multirow[t]{2}{*}{$p$-value } \\
\hline & $\begin{array}{c}\text { Yes } \\
n=62(\%)\end{array}$ & $\begin{array}{c}\text { No } \\
n=41(\%)\end{array}$ & & $\begin{array}{c}\text { Yes } \\
n=52(\%)\end{array}$ & $\begin{array}{c}\text { No } \\
n=51(\%)\end{array}$ & \\
\hline \multicolumn{7}{|c|}{$\begin{array}{l}\text { Seen any SOPs of } \\
\text { infection } \\
\text { control/prevention }\end{array}$} \\
\hline Yes & $12(19)$ & $36(88)$ & \multirow[t]{2}{*}{0.338} & $\begin{array}{c}6(12) \\
46(88)\end{array}$ & $\begin{array}{l}11(22) \\
40(78)\end{array}$ & \multirow[t]{2}{*}{0.170} \\
\hline \multicolumn{5}{|c|}{$\begin{array}{l}\text { Had in-service } \\
\text { training SOPs }\end{array}$} & & \\
\hline Yes & $16(26)$ & $17(41)$ & & $18(35)$ & $15(29)$ & \multirow{3}{*}{0.571} \\
\hline No & $46(74)$ & $24(59)$ & 0.096 & $34(65)$ & $36(71)$ & \\
\hline No & $1(2)$ & $5(12)$ & & $3(6)$ & $3(6)$ & \\
\hline
\end{tabular}

p-values obtained from chi-square test.

Table 10. Individual factors associated with compliance to SPIC at bivariate analysis.

\begin{tabular}{|c|c|c|c|c|c|c|}
\hline \multirow[b]{2}{*}{ Variables } & \multicolumn{2}{|c|}{ Hand Hygiene } & \multicolumn{2}{|c|}{ Use of PPE } & \multicolumn{2}{|c|}{$\begin{array}{l}\text { Disinfection of re-usable equipment } \\
\text { and cleaning of delivery surfaces }\end{array}$} \\
\hline & OR $95 \% \mathrm{CI}$ & $P$-value & OR $95 \% \mathrm{CI}$ & $P$-value & OR $95 \% \mathrm{CI}$ & $P$-value \\
\hline \multicolumn{7}{|l|}{ Gender } \\
\hline Male & 1.00 & & 1.00 & & 1.00 & \\
\hline Female & 1.00 & 0.172 & $0.33(0.06-1.17)$ & 0.190 & $0.29(0.07-1.05)$ & 0.060 \\
\hline \multicolumn{7}{|c|}{ Work experience in years } \\
\hline$<1$ & 1.00 & & $2.8(0.24-33.04)$ & 0.414 & $2.03(0.53-7.73)$ & 0.302 \\
\hline $2-4$ & $1.2(0.10,14.69)$ & 0.887 & $2.33(0.13-40.46)$ & 0.561 & $1.01(0.25-4.17)$ & 0.986 \\
\hline $5-10$ & $3.8(0.32,44.51)$ & 0.288 & $1.51(0.13-17.54)$ & 0.740 & $1.50(0.51-4.43)$ & 0.463 \\
\hline$>10$ & $2.8(0.24,33.04)$ & 0.414 & 1.00 & & 1.00 & \\
\hline
\end{tabular}

$p$-values and odds ratios obtained from logistic regression.

experience of 5 years and below were two times more likely to comply with hand hygiene and disinfection of re-usable equipment than those with more than five years work experience.

In Table 11, indicate results from cross tabulation for waste segregation of sharps, waste segregation excluding sharps and observing the non-touch technique. Results show that profession cadre was associated with waste segregation of sharps statistically significant with $p$-values $<0.029$ for obstetricians. It is also indicated in Table 11 that work experience of 2 - 4 years was also significantly associated ( $p$-value 0.043 ) with waste segregation of sharps. Gender was significantly associated with compliance to waste segregation excluding sharps ( $p$-value 
$<0.001)$. In the same table, professional cadre was significantly associated with compliance with waste segregation $p$-value 0.005 for midwives and $p$-value < 0.001 for obstetricians. Results also indicate that professional cadre (midwife) was statistically associated with observing the non-touch technique with a $p$-value of 0.048 .

Table 12 below results reveal that having seen Standard Operating Procedures (SOPs), was two times more likely to comply with observing the non-touch technique that those who had not.

\section{Multivariate Analysis}

Multivariate analysis was carried out to control for confounders using only

Table 11. Individual factors associated with compliance with SPIC in bivariate analysis.

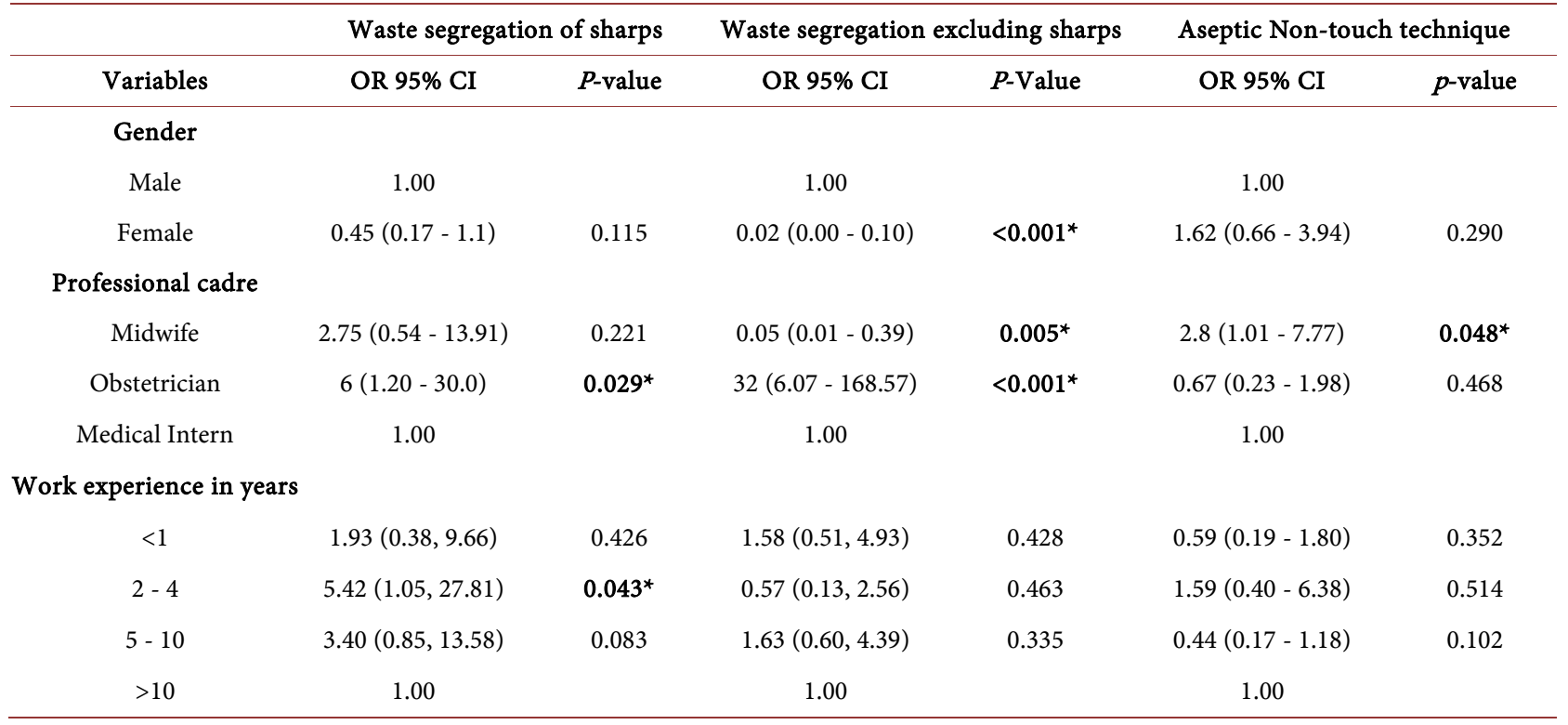

$p$-values and odds ratios obtained from logistic regression. ${ }^{*}$ indicates significant findings because the $p$-value $<0.05$.

Table 12. Hospital/facility factors associated with SPIC in the management of labour by healthcare workers at bivariate analysis.

\begin{tabular}{ccccccc}
\hline \multirow{2}{*}{ Variables } & \multicolumn{2}{c}{$\begin{array}{c}\text { Waste segregation } \\
\text { of sharps }\end{array}$} & \multicolumn{2}{c}{$\begin{array}{c}\text { Waste segregation } \\
\text { excluding sharps }\end{array}$} & \multicolumn{2}{c}{$\begin{array}{c}\text { Aseptic Non-touch } \\
\text { technique }\end{array}$} \\
\cline { 2 - 7 } & OR 95\% CI & $p$-value & OR 95\% CI & $p$-value & OR 95\% CI & $p$-value \\
\hline $\begin{array}{c}\text { Seen any SOPs of } \\
\text { infection control }\end{array}$ & & & & & & \\
Yes & $0.71(0.18-2.71)$ & 0.613 & $0.58(0.19-1.78)$ & 0.342 & $2.11(0.72-6.22)$ & 0.176 \\
No & 1.00 & & 1.00 & & 1.00 & \\
Had in-service \\
training in SPIC \\
Yes
\end{tabular}

Odds ratios and $p$-values obtained from logistic regression. ${ }^{*}$ indicates significant findings because the $p$-valve $<0.05$. 
the independent variables that had shown significant relationship with the outcome variable in bivariate analysis. A few factors were analyzed at once and by removing one and adding another factor such that the same factors are not analyzed together. Results are presented in Table 13 below. Results in Table 13 below indicate that, having had an in-service training was statistically associated with compliance to hand hygiene.

Table 14 below indicates results obtained from multivariate analysis of the association of waste segregation excluding sharps. Results show that being a female was statistically significant with waste segregation excluding sharps $(p=0.000)$.

\section{Discussion}

\subsection{Individual Factors Associated with Compliance to Standard Precautions of Infection Control in Management of Labour by Healthcare Workers}

The social demographic characteristics in this study were also regarded as individual factors. Data from 103 study participants were analysed. Results indicate

Table 13. Multivariate analysis of the association of Hand hygiene technique.

\begin{tabular}{cccc}
\hline Variables & Odds ratio & 95\% C.I & $p_{\text {-value* }}$ \\
\hline Work experience (in years) & & & \\
$\leq 1$ & 1.14 & $(0.05-24.96)$ & 0.932 \\
$2-4$ & 7.41 & $(0.23-237.72)$ & 0.258 \\
$5-10$ & 7.00 & $(0.10-472.57)$ & 0.365 \\
$>10$ & 1.00 & & \\
Had in-service training on SPIC & & & $\mathbf{0 . 0 1 2 ^ { * }}$ \\
Yes & 0.04 & $(0.003-0.49)$ & \\
No & 1.00 & & \\
\hline
\end{tabular}

$p$-values obtained from a logistic regression. ${ }^{*}$ indicates significant findings because the $p$-value $<0.05$.

Table 14. Multivariate analysis of the association of waste segregation excluding sharps.

\begin{tabular}{cccc}
\hline Variables & Odds ratio & $95 \%$ C.I & $p$-value* \\
\hline Gender & 1.00 & & \\
Male & 0.015 & $(0.00-0.08)$ & $0.001^{*}$ \\
Female & & & \\
$\begin{array}{c}\text { Seen any SOPs of infection } \\
\text { control/prevention }\end{array}$ & 0.212 & $(0.04-1.24)$ & 0.086 \\
Yes & 1.00 & & \\
No & & & 0.054 \\
Yes & 3.869 & $(0.97-15.36)$ & \\
No & 1.00 & &
\end{tabular}

$p$-values obtained from a logistic regression ${ }^{*}$ indicates significant findings because the $p$-value $<0.05$. 
that the majority of the study participants were females at $74 \%$, this could have been due to the fact that majority according to professional cadre were midwives (48\%). According to the Ugandan training system in midwifery education, entry requirements suggest that one should be a female in order to be enrolled in the training program. According to Kopolo et al. (2005), females are seen to be more in the clinical practice of the healthcare system and the males in administrative and policy levels.

This study demonstrated that compliance with standard precautions of infection control was generally highly associated with the above mentioned. Although the overall score was low, obstetricians in all the domains of SPIC had lower scores compared to other professional cadres for example in the hand hygiene domain where $100 \%$ of this cadre did not comply. This could have been as a result of work overload as it is indicated in Uganda the doctor patient ratio currently stands at 1:25,725 (UDHS, 2016).

It was found that majority of the medical intern (60\%) were more compliant with hand hygiene compared to other professional cadres. The findings in this study were also congruent with those a study done in Jordan [19] which found out that nurses had significant higher compliance than physicians with mean= $4.91(p=004)$.

In our study, females scored higher than males in overall compliance with a statistically significance difference. This was in agreement with a study done in Jordan about factors influencing compliance with infection control precautions among 211 nurses and physicians from private and public hospitals, it was indicated that there was a significant positive correlation between compliance and individual factors such as gender where being a female was likely to be associated with compliance to SPIC. The female HCWs' compliance with SPIC might be due to the natural proneness of female employee to obey and execute institutional rules and regulations [10]. Moreover, in Uganda women take a major role in cleaning, cooking and caretaking this could make them cautious about infection control and prevention to their family. of their family Females are usually seen performing duties that require cleanliness as part of their gender roles.

In this study work experience of 2 - 4 years was significantly ( $p$ value 0.043 ) associated with compliance with waste segregation of sharps. This is in contrast with pertinent studies where having more experience in clinical services was found to be significantly associated with compliance. For instance a study done in India [20] which indicated length of time was statistically significant with compliance $(p=0.014)$ where those who had longer stay on job had better compliance. Our study findings of a short work experience could be related to the fact that these healthcare workers are fresh graduates and inspired in applying knowledge into skills, this could also be explained by the Bloom's taxonomy of the learning domains, where the higher the level of learning, the more the learners will tend to apply more of the psychomotor domain. 
Results in this study, indicated that work in multiple places influenced compliance with hand hygiene and segregation of waste excluding sharps negatively. It was apparent that respondents working in multiple places showed lower compliance scores compared to those who did not. Work overload has also been found to influence stress and hence decrease competence among healthcare workers [21]. This could be due to the fact that, Mulago as a national referral hospital, receives an overwhelmingly huge numbers of mothers in labour yet there is inadequate staffing. In Uganda currently the doctor-patient ratio stands at 1:25,725 and nurse-patient ratio at 1:11,000 (UBOS, 2012). The doctors tend to get involved in dual practice in order for them to cope with low pay in the public health facilities such as Mulago National Referral Hospital. The results from this study agree with previous studies such as study conducted in Brazil [22] and another study in China [23], while a study done in Italy [24] showed lower scores of $15 \%$ among healthcare workers who had a side job. This conforms to Piai-Morais et al. (2015) in his conclusion that work overload negatively affects compliance.

In this study, aseptic non-touch technique showed statistical significance with professional cadre and level of education both at Univariate and at bivariate analysis. It was also indicated that Obstetricians were 6 times more likely to comply with the asepsis non-touch technique compared to the midwives. Aseptic non-touch technique is one of the core components of SPIC, which involves a set of actions, aimed at preventing transmission of pathogenic infections to the patient (CDC, 2010). Aseptic non-touch technique vocabulary has been used interchangeably with other words which changes meaning and causes confusion which could contribute to practice variability [25]. The results from this were in congruent with the findings from a study done on two London hospitals [25] where Physicians were more compliant than the nurses in observing the non-touch technique. This could be explained by the different training systems that could have an impact on the practice outcomes especially when it comes to clinical practice [26].

\subsection{Hospital Related Factors Associated with Compliance to Standard Precautions of Infection Control in the Management of Labour}

In this study, it was also found out that having had an in-service training on standard precautions of infection, control and having seen SOPs were associated to compliance with waste segregation of sharps, waste segregation excluding sharps and observing the Aseptic non-touch technique. The Odds Ratios at bivariate analysis indicated those who had seen SOPs and those who had gone through in-service training in SPIC were two times more likely to comply with these domains of standard precautions of infection control. The main purpose of standard operating procedures is to inform all healthcare workers of the correct steps to follow during the practice of SPIC this is also seen to improve knowledge on SPIC [27]. In a quasi-experimental study on the effectiveness of SOPs 
in prevention of needle stick injury among nurses in an Indian hospital, results showed improvement in knowledge between day 9 and 70 with post score of (22.26) on day 70 [27]. In our study, there was significant association between compliance with SPIC and having seen SOPs at Univariate, bivariate and multivariate analysis. This phenomenon is best explained by the behaviourist theory of learning where learning actually occurs when new behaviours are acquired through associations between stimuli. This means that having received training on SPIC, the SOP will be a reminder for the healthcare worker. The WHO (2016) strongly emphasizes that standard operating procedures are in place in all healthcare service delivery systems.

This proves the opportunity to train healthcare workers in SPIC and the management's commitment on patient safety during stay in hospital with aim of preventing Hospital Acquired Infections (HAIs). Training of HCWs on SPIC is a fundamental and immediate need. This need can be identified in a study done in China [23] among 144 nurses where it was evident that less than half of the participants were knowledgeable about SPIC and $98.20 \%$ expressed interest to be trained in such measures.

It was also apparent in a recent pragmatic evaluation study in 2 London hospitals [25] where a bigger proportion of staff $(37 / 49,76 \%)$, thought that their practice had greatly improved and $98 \%$ of these staff considered the training had helped to standardize aseptic technique practices.

Similar findings were shown in a study done in Brazil [22] where practice of SPIC was highly influenced by availability of standard operating procedures at the hospital and continuous medical training on SPIC. In contrary, an observation study on compliance with infection control and prevention in Kenya Bedoya et al., (2017), concluded that there was a weak association between compliance and availability of all infection control supplies. In service training to all healthcare workers, despite of their professional cadres and academic qualification is vital concerning infection control and prevention in labour suites in order to prevent hospital-acquired infections to all mothers who are in labour.

The results from this study reveal lack of strategic approach for infection control and prevention in the labour suites of Mulago national referral hospital. It was shown in this study that there are no standard operating guidelines in this institution, yet there are several strategies set by the WHO for infection control and prevention in maternal health facilities for developing countries [1]. These strategies include development of an institutional infection control programme which consist of use of infection control and prevention manuals, education and training of HCWs, infection control teams and committees and audit of maternal deaths [28].

\section{Study Limitations}

This study had the following limitations:

Compliance was measured by direct observation, which would bring about the Hawthorne's effect among the study participants, to minimize on this the re- 
searcher utilized direct unobtrusive observation when the healthcare workers performed their procedures in care for mothers in labour.

The other limitation is that the study was cross-sectional in nature, which does not establish the definitive and effect of a relationship between the dependent, and independent variables, this was maximized by combining observation together with interviews from researcher-administered questionnaire.

\section{Strengths of the Study}

According to my understanding, this study was the first to determine compliance with standard precautions of infection control in management of labour by healthcare workers in Uganda and sub-Saharan Africa.

Compliance was measured by direct observation, which has been considered a gold standard to measure compliance by various researchers.

\section{Conclusions}

Overall compliance to standard precautions of infection control was low at 52\% although it varied across domains.

The findings in this study provide insight into individual and hospital related factors associated with compliance with standard precautions of infection control in management of labour. These factors include: gender, professional cadre, level of education, having had n-service training and availability of supplies for infection control measures at the institution.

\section{Recommendations}

Based on the above findings in the study, the following recommendations were made

1) There is an urgent need to put up interventions to improve on compliance with SPIC in management of labour among all healthcare workers because mothers in labour are at very high risk to acquisition of infections during this course of childbirth.

2) Establishment of appropriate strategies and policies which include; accountable infection control committee/team, regular in-service training of HCWs in SP, adequate supply of PPE and provision standard operating procedures in all parts of the facility

\section{Implications for Practice}

As healthcare workers it is very important to observe compliance with standard precautions of infection control in the management of labour since were in the best position to control/prevent hospital-acquired infection. There's need to strengthen policies regarding infection control and prevent at all levels of management.

\section{Conflicts of Interest}

The authors declare no conflicts of interest regarding the publication of this paper. 


\section{References}

[1] Abdulraheem, I., Amodu, M., Saka, M., Bolarinwa, O. and Uthman, M. (2012) Knowledge, Awareness and Compliance with Standard Precautions among Health Workers in North Eastern Nigeria. Journal of Community Medicine and Health Education, 2, 131.

[2] Bedoya, G., Dolinger, A., Rogo, K., Mwaura, N., Wafula, F., Coarasa, J., Das, J., et al. (2017) Observations of Infection Prevention and Control Practices in Primary Health Care, Kenya. Bulletin of the World Health Organization, 95, 503-516. https://doi.org/10.2471/BLT.16.179499

[3] Bowmer, G., Latchford, G., Duff, A., Denton, M., Dye, L., Lawton, C. and Lee, T. (2017) Adherence to Infection Prevention and Control Guidelines: A VignetteBased Study of Decision-Making and Risk-Taking in Young Adults with Cystic Fibrosis. Journal of Cystic Fibrosis, 16, 146-150.

https://doi.org/10.1016/j.jcf.2016.09.001

[4] Choi, E., Lindquist, R. and Song, Y. (2014) Effects of Problem-Based Learning vs. Traditional Lecture on Korean Nursing Students; Critical Thinking, Problem-Solving, and Self-Directed Learning. Nurse Education Today, 34, 52-56. https://doi.org/10.1016/j.nedt.2013.02.012

[5] Clare, S. and Rowley, S. (2018) Implementing the Aseptic Non Touch Technique $\left(\mathrm{ANTT}^{\circledast}\right)$ Clinical Practice Framework for Aseptic Technique: A Pragmatic Evaluation Using a Mixed Methods Approach in Two London Hospitals. Journal of Infection Prevention, 19, 6-15. https://doi.org/10.1177/1757177417720996

[6] Friday, O., Edoja, O., Osasu, A., Chinenye, N., Cyril, M., Lovney, K. and Julia, H. (2012) Assessment of Infection Control Practices in Maternity Units in Southern Nigeria. International Journal for Quality in Health Care, 24, 634-640. https://doi.org/10.1093/intqhc/mzs057

[7] Gammon, J., Morgan-Samuel, H. and Gould, D. (2008) A Review of the Evidence for Suboptimal Compliance of Healthcare Practitioners to Standard/Universal Infection Control Precautions. Journal of Clinical Nursing, 17, 157-167.

[8] Gordis, L. (2009) Epidemiology. Saunders Elsevier, Philadelphia.

[9] Graham, W.J., Morrison, E., Dancer, S., Afsana, K., Aulakh, A., Campbell, O.M., Fekad, B., et al. (2016) What Are the Threats from Antimicrobial Resistance for Maternity Units in Low- and Middle-Income Countries? Global Health Action, 9, Article ID: 33381. https://doi.org/10.3402/gha.v9.33381

[10] Haile, T.G., Engeda, E.H. and Abdo, A.A. (2017) Compliance with Standard Precautions and Associated Factors among Healthcare Workers in Gondar University Comprehensive Specialized Hospital, Northwest Ethiopia. Journal of Environmental and Public Health, 2017, Article ID: 2050635. https://doi.org/10.1155/2017/2050635

[11] Haridi, H.K., Al-Ammar, A.S. and Al-Mansour, M.I. (2016) Compliance with Infection Control Standard Precautions Guidelines: A Survey among Dental Healthcare Workers in Hail Region, Saudi Arabia. Journal of Infection Prevention, 17, 268-276. https://doi.org/10.1177/1757177416645344

[12] Ith, P., Dawson, A. and Homer, C. (2012) Quality of Maternity Care Practices of Skilled Birth Attendants in Cambodia. International Journal of Evidence-Based Healthcare, 10, 60-67. https://doi.org/10.1111/j.1744-1609.2012.00254.x

[13] Ith, P., Dawson, A., Homer, C.S. and Whelan, A.K. (2013) Practices of Skilled Birth Attendants during Labour, Birth and the Immediate Postpartum Period in Cambodia. Midwifery, 29, 300-307. https://doi.org/10.1016/j.midw.2012.01.010

[14] Jawaid, M., Iqbal, M. and Shahbaz, S. (2009) Compliance with Standard Precau- 
tions: A Long Way Ahead. Iranian Journal of Public Health, 38, 85-88.

[15] Jones, M., Whitfield, A., Thomas, S., Gower, S. and Michael, R. (2014) Educational Innovation for Infection Control in Tanzania: Bridging the Policy to Practice Gap. Journal of Infection Prevention, 15, 94-98. https://doi.org/10.1177/1757177413516525

[16] Kaushik, A. and Jyoti, S. (2017) A Quasi Experimental Study to Assess the Effectiveness of Standard Operating Procedures on Prevention and Management of Needle Stick Injury in a Teaching Hospital of Haryana, India. International Journal of Research in Medical Sciences, 3, 3069-3073. https://doi.org/10.18203/2320-6012.ijrms20151125

[17] Kermode, M., Jolley, D., Langkham, B., Thomas, M.S., Holmes, W. and Gifford, S.M. (2005) Compliance with Universal/Standard Precautions among Health Care Workers in Rural North India. American Journal of Infection Control, 33, 27-33. https://doi.org/10.1016/j.ajic.2004.07.014

[18] Koshy, S. and Patel, R. (2015) Effectiveness of Planned Teaching Program on Knowledge Regarding the Infection Control Measures in Labour Room among the Staff Nurses Working in Maternity Unit in Selected Hospital of Panchmahal District. International Journal of Innovative Research and Development, 4, 29-41.

[19] Luo, Y., He, G.-P., Zhou, J.-W. and Luo, Y. (2010) Factors Impacting Compliance with Standard Precautions in Nursing, China. International Journal of Infectious Diseases, 14, e1106-e1114. https://doi.org/10.1016/j.ijid.2009.03.037

[20] Mahmood, A., Rehman, B. and Chughtai, F. (2008) A Survey of Infection Control Practices in the Delivery Room and Nursery to Investigate and Control the High Rate of Neonatal Sepsis: An Experience at a Secondary Care Hospital. The Journal of the Pakistan Medical Association, 58, 237.

[21] Nofal, M., Subih, M. and Al-Kalaldeh, M. (2017) Factors Influencing Compliance to the Infection Control Precautions among Nurses and Physicians in Jordan: A Cross-Sectional Study. Journal of Infection Prevention, 18, 182-188. https://doi.org/10.1177/1757177417693676

[22] Mehta, R., Mavalankar, D.V., Ramani, K., Sharma, S. and Hussein, J. (2011) Infection Control in Delivery Care Units, Gujarat State, India: A Needs Assessment. BMC Pregnancy and Childbirth, 11, 37. https://doi.org/10.1186/1471-2393-11-37

[23] Ngonzi, J., Tornes, Y.F., Mukasa, P.K., Salongo, W., Kabakyenga, J., Sezalio, M., Van Geertruyden, J.-P., et al. (2016) Puerperal Sepsis, the Leading Cause of Maternal Deaths at a Tertiary University Teaching Hospital in Uganda. BMC Pregnancy and Childbirth, 16, 207. https://doi.org/10.1186/s12884-016-0986-9

[24] Nofal, M., Subih, M. and Al-Kalaldeh, M. (2017) Factors Influencing Compliance to the Infection Control Precautions among Nurses and Physicians in Jordan: A Cross-Sectional Study. Journal of Infection Prevention, 18, 182-188. https://doi.org/10.1177/1757177417693676

[25] Numminen, O., Ruoppa, E., Leino-Kilpi, H., Isoaho, H., Hupli, M. and Meretoja, R. (2016) Practice Environment and Its Association with Professional Competence and Work-Related Factors: Perception of Newly Graduated Nurses. Journal of Nursing Management, 24, E1-E11. https://doi.org/10.1111/jonm.12280

[26] Organization, W.H. (2016) WHO Recommendations for Prevention and Treatment of Maternal Peripartum Infections.

[27] Parmeggiani, C., Abbate, R., Marinelli, P. and Angelillo, I.F. (2010) Healthcare Workers and Health Care-Associated Infections: Knowledge, Attitudes, and Behavior in Emergency Departments in Italy. BMC Infectious Diseases, 10, 35. 
https://doi.org/10.1186/1471-2334-10-35

[28] Piai-Morais, T.H., Orlandi, F.D.S. and Figueiredo, R.M.D. (2015) Factors Influencing Adherence to Standard Precautions among Nursing Professionals in Psychiatric Hospitals. Revista da Escola de Enfermagem da USP, 49, 473-480.

https://doi.org/10.1590/S0080-623420150000300016 


\section{Appendix I: Observation Checklist}

CHECKLIST CODE

PERSONAL DATA OF THE HEALTHCARE WORKER

Profession.

Cadre....

Qualification.

Sex.

Date and time

Table A1: Indications for standard precautions of infection control practices, actions and equipment and supplies required for compliance during the management of labour at Mulago National Referral Hospital, Uganda.

1) Indication means a situation in which an infection control and prevention measure has to be undertaken.

2) Corresponding action is the measure the health care worker took in response to an indication where by yes (performed) and no (not performed)

Total compliance means the respondent has scored at least 10/10 of the corresponding actions in response to indications

Table A1. Observation checklist for SPIC.

Standard precaution of infection control domain and indication

\section{Hand hygiene}

1) Before touching the patient

2) Between patient contact

3) Before a clean or aseptic procedure

4) After contact with an object that has touched the patient or was in the patient's immediate environment

5) Before an invasive procedure (injection, Cannulation and catheterization)

6) Emmediately after removal of gloves

Total compliance

Use of Personal Protecting Equipment (PPE) and antiseptic solutions

7) Sterile gloves before vaginal examination

8) exposure to body fluids

9) sterlile gloves, eyewear, plastic apron, covered shoes while conducting a vaginal delivery

10) Use of freshly prepared ant septic solution to clean the perineum before vaginal examination

\section{Total compliance}

Equipment disinfection and cleaning of delivery surfaces

Cleaned the delivery surface using a disinfectant using a swipe technique

11) Before and after contact with patient (thermometer) 


\section{Continued}

12) before and after patient contact (fetoscope)

13) Before and after patient contact (stethoscope)

14) after patient contact (needle holder, forceps, episiotomy scissors) placed in a disinfectant for 10 minutes

Total compliance

Waste segregation of sharps

15) After an injection needle placed in the sharps container

16) after cannulation the sharps placed in the sharps container

17) After use of a surgical blade placed in the sharps container

Total compliance

Waste segregation, excluding sharps

18) After an invasive procedure and infectious waste was produced and was discarded in a respective bin

19) after use of a non-reusable equipment (speculum, gloves, catheters) discarded in the corresponding bin

20) after delivery of the placenta, it was discarded in the corresponding bin

Total compliance

Non touch technique

21) During invasive procedures and handling of sterile equipment and linen

Total Compliance

\section{Appendix II: Questionnaire}

Questionnaire about individual factors associated with compliance with standard precautions of infection control in management of labour by healthcare workers

Date Time.

Healthcare worker's' study code

\section{Section A: individual factors}

\begin{tabular}{lll}
\hline$\# \quad$ Questions & \multicolumn{1}{c}{} \\
\hline Q3 Gender & $1=$ Male \\
& $2=$ Female \\
& $1=$ Midwife \\
& $2=$ Nurse \\
Q4 What is your profession? & $3=$ Nurse-midwife \\
& $4=$ Medical officer \\
& $5=$ Obstetrician \\
& $1=$ Certificate \\
& $2=$ Diploma \\
Q5 $\quad$ What is your level of qualification? & $3=$ Bachelor's degree \\
& $4=$ Master's degree \\
\end{tabular}




\section{Continued}

\begin{tabular}{ll}
\hline & $1=\leq 1$ year \\
Q6 What is your work experience? & $2=2-4$ years \\
& $3=5-10$ years \\
$4=\geq 10$ years \\
Q7 Do you have a side job? & $1=$ Yes \\
& $2=$ No \\
\hline
\end{tabular}

\section{Section B: Hospital/facility related factors}

\begin{tabular}{cll}
\hline \multirow{2}{*}{ Q08 } & $\begin{array}{l}\text { Have you ever seen any standard operating procedures } \\
\text { of infection control and prevention in this facility? }\end{array}$ & $\begin{array}{l}1=\text { Yes } \\
2=\text { No }\end{array}$ \\
\multirow{2}{*}{ Q09 } & Have you ever had an in service training on standard & $1=$ Yes \\
& precautions of infection control in this hospital? & $2=$ No \\
\hline
\end{tabular}

